\title{
Light Entrapping, Modeling \& Effect of Passivation on Amorphous Silicon Based PV Cell
}

\author{
http://dx.doi.org/10.3991/ijes.v4i2.5848 \\ Md. Mostafizur Rahman, Md. Moidul Islam, Mission Kumar Debnath, \\ S.M. Saifullah, Samera Hossain, Nusrat Jahan Bristy \\ American International University-Bangladesh (AIUB), Dhaka, Bangladesh.
}

\begin{abstract}
This research paper present efforts to enhance the performance of amorphous silicon p-i-n type solar cell using sidewall passivation. For sidewall passivation, MEMS insulation material $\mathrm{Al}_{2} \mathrm{O}_{3}$ was used. The main objective of this paper is to observe the effect of sidewall passivation in amorphous silicon solar cell and increase the conversion efficiency of the solar cell. Passivation of $\mathrm{Al}_{2} \mathrm{O}_{3}$ is found effective to subdue reverse leakage. It increases the electric potential generated in the designed solar cell. It also increases the current density generated in the solar cell by suppressing the leakage. Enhancement in $\mathrm{J}-\mathrm{V}$ curve was observed after adding sidewall passivation. The short circuit current density $\left(J_{\text {sc }}\right)$ increased from $14.7 \mathrm{~mA} / \mathrm{cm}^{2}$ to 18.5 $\mathrm{mA} / \mathrm{cm}^{2}$, open circuit voltage $\left(\mathrm{V}_{\mathrm{oc}}\right)$ improved from $0.87 \mathrm{~V}$ to $0.89 \mathrm{~V}$, and the fill factor also slightly increased. Due to the sidewall of passivation of $\mathrm{Al}_{2} \mathrm{O}_{3}$, conversion efficiency of amorphous silicon solar cell increased by $29.07 \%$. At the end, this research was a success to improve the efficiency of the amorphous silicon solar cell by adding sidewall passivation.
\end{abstract}

Index Terms-Amorphous Silicon, Passivation, Aluminum Oxide, Electric Potential, Current Density, COMSOL Multiphysics.

\section{INTRODUCTION}

The greater part of the world's recent electricity supply is generated from fossil fuels like oil, coal and natural gas. These energy resources are faced by a number of challenges which includes rising of these fuels, security issues etc. The epic challenge of the $21^{\text {st }}$ century is to fill up the gap between energy supply and demand with clean, reliable and inexpensive renewable energy. Therefore researcher started to implement alternative energy resources for long being and the renewable energy is one of them and Solar System is one of the clean alternative resources. While we started our research work, several challenges like reducing environmental impact, increasing conversion efficiency is the main concern of our work which are important for environmental impact and also for energy sources. Semi-conductors are promising for photovoltaic applications. Many semi-conductors are abundant, nontoxic and chemically stable that allows materials disposal under ambient conditions.

Amorphous silicon (a-Si or a-Si:H) solar cells are introduced as a category of thin film solar cells. The word "amorphous" actually signify shapeless. In this type of solar panels, silicon is not crystallized or structured on molecular level like the other types of solar cells based on silicon material. Hydrogenated amorphous silicon (a-Si:H) was a late arrival to the research on amorphous semicon- ductors, which was first made in the late 1960s. Before that time there was research on amorphous silicon without hydrogen, which was prepared by sputtering or by thermal evaporation. The unhydrogenated material has a very high defect density which prevents doping, photoconductivity, and the other desirable characteristics of useful semiconductor. Electronic measurement was mostly limited to the investigation of conduction through the defect states [2].

Though amorphous silicon suffers from lower electric performance compared to c-Si but it is more flexible in its application. For example if more a-Si layer is used to make solar cell than c-Si then it saves the silicon material producing cost and it can be recycled [10] [11].

In this research sidewall passivation or insulating was introduced in a-Si solar cell. Passivation is extremely necessary for high efficiency solar cells. Films of a-Si have proved to be on par with the best dielectric films and for intrinsic films, an essential state for good passivation is that the interface is atomically sharp for flat and also for textured substrates.

Effective reduction of front surface carrier recombination is essential for high efficiency silicon solar cells. Dielectric films are normally used to achieve such reduction. These provide an efficient passivation of surface recombination and an effective anti-reflection layer. The conditions that produce an effective anti-reflection coating are not necessarily the same for efficient passivation, hence both functions are difficult to achieve simultaneously and expensive processing steps are normally required. This can be overcome by enhancing the passivation properties of an anti-reflective film using the electric field effect. Here, we demonstrate that thermally grown Aluminum oxide $\left(\mathrm{Al}_{2} \mathrm{O}_{3}\right)$ is an efficient passivation layer when chemically treated and electrically charged. Double layers of $\mathrm{Al}_{2} \mathrm{O}_{3}$ also provided stable and efficient passivation for a period of a year when the sample is submitted to a postcharge anneals [3].

Scientists have published the efficiency rates of the amorphous silicon cells to $12.5 \%$. These solar cells are manufactured in ranges from $6 \%$ to $9 \%$ in high volume processes [1]. To produce electricity; the thin film solar cells make use of only a 1-4 $\mu \mathrm{m}$ thick layer of semiconductor substance. For this reason these require less processing and less materials.

This paper is organized as follows: Section 2 presents a review of amorphous silicon based solar cell. Section 3 describes the experimental design of a-Si solar cell and materials used in the cell. This section presents two designs of a-Si solar cell. One design is without any sidewall passivation and other one is modified design of the solar 
cell with sidewall passivation. Section 4 represents the analysis of the simulated results. With Section 5 this paper ends with a conclusion.

\section{REVIEW OF AMORPHOUS SILICON PV CELL}

Light is an energy that consists of photons. Solar cells convert this light energy into direct current (DC) and voltages. The conventional solar cells are made of silicon. It is a semi-conductor material which means it has a property of both metal and insulator.

Generally solar cells are made by Si which are flat plate and most efficient. Amorphous solar cell is called descend generation solar cell Non-crystalline form of silicon material is called amorphous silicon. Each silicon atom is connected with four neighboring silicon atom through covalent bond. So it is called fourfold coordinated atom. It is the tetrahedral bonded of silicon atoms to bond with neighboring silicon. But for the amorphous silicon this type of long range order is not present. Rather than this type atom create a random network continuously [5]. Although all atoms are not fourfold coordinated with amorphous silicon. For this disorder behavior of the natural material, some of the atoms of these materials have dangling bond represents the defect of the material which is used in PV cells [6]. Crystalline silicon PV cell is one type of heterojunction technology which allows these solar cells to convert energy. This type of solar cell is composed of thin amorphous Si layer on monocrystalline silicon wafer. Amorphous silicon band gap is more than crystalline silicon. It helps to reduce the C-Si density and doping process for this type of film is easy. 1/300 th amount of active material is contained by amorphous silicon cell in the crystalline silicon solar cell.

Amorphous silicon modules are the first truly commercial thin-film photovoltaic (PV) devices. For the deposition of amorphous silicicon from silane or other silicon gases several methods have been used.These include: chemecal vapor chemical vapor deposition (CVD), direct current (de) and radio-frequency (rf) glow discharge (plasma-enhanced chemical vapor deposition), electron-cyclotron-resonance (ECR) glow discharge, microwave glow discharge, hot-wire decomposition sputtering and cluster beam evaporation. Of these, rf and de glow-discharge depositions are the most common and are those used by industry. Glow discharge has demonstrated ease of scale-up and excellent uniformity over square-meter areas [12].

Amorphous silicon panels are created of thin layer of silicon material by chemical vapor deposition. Thickness of this layer is about 1 micrometer on a substrate like a glass or metal. At low temperature which is $75^{\circ} \mathrm{C}$, it can be deposited at this temperature which helps to deposit on a plastic or other metal [7]. However, on heating the samples to above $150^{\circ} \mathrm{C}$ the effect could reverse. This type of cell is the simplest form of the cell structure which sequence is p-i-n layer. Single layer surface has the possibility to give the minimum output with the range of 15 $35 \%$. When it is exposed to the sun .This type of problem is called degradation. And the mechanism of the degradation is known as Staebler-Wronski effect [7]. Thin layer is used across the material for increasing the electric field strength and better stable output. As a result light absorption reduces with the side of cell efficiency.

\section{EXPERIMENTAL DESIGN}

It is important to analyze the performance of amorphous silicon based solar cell before adding any sidewall passivation. So the performance of the new designed model can be compared to observe the enhancement. All the simulations were done using COMSOL Multiphysics.

Initially pin type amorphous silicon solar cell was designed to observe the performance without passivation. The designed model consisted of front TCO (Transparent conductive oxide), back TCO and back reflector. The designed model has Fluorine doped $\mathrm{SnO}_{2}\left(\mathrm{SnO}_{2}: \mathrm{F}\right)$ in the front TCO. In back TCO Aluminium doped $\mathrm{ZnO}$ ( $\mathrm{ZnO}: \mathrm{Al})$ and in back reflector silver $(\mathrm{Ag})$ was used. Figure 1(a) shows the geometrical design of the solar cell designed without any passivation.

Then sidewall passivation was introduced in the design. $\mathrm{Al}_{2} \mathrm{O}_{3}$ insulator material was used for sidewall passivation. Figure 1(b) shows the design of the solar cell with sidewall passivation.

Both structures shown in figure 1 consisted of $100 \mathrm{~nm}$ of both front TCO \& back TCO and $200 \mathrm{~nm}$ of back reflector. Width of the sidewall passivation was $20 \mathrm{~nm}$. Table I explains about the thickness and materials used in different layers.

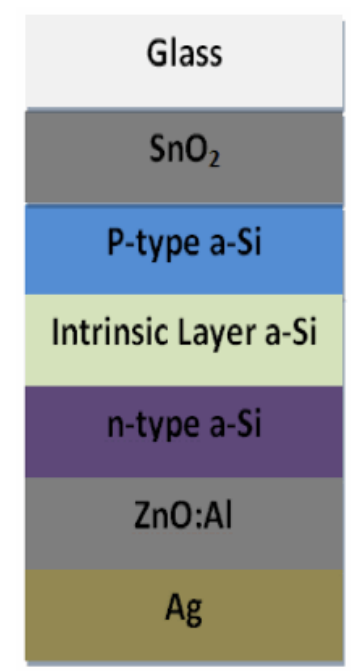

(a)

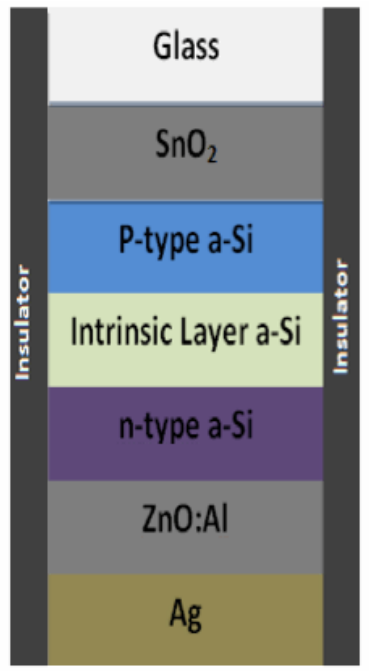

(b)
Figure 1. Schematic of designed a-Si solar cell without passivation (a) $\&$ designed a-Si solar cell with sidewall passivation (b).

TABLE I.

NAME OF THE LAYERS, MATERIALS \& THICKNESS OF THE LAYERS

\begin{tabular}{|c|c|c|}
\hline Layer & Material Used & Thickness \\
\hline Glass & Glass & $300 \mathrm{~nm}$ \\
\hline Front TCO & $\mathrm{SnO}_{2}: \mathrm{F}$ & $100 \mathrm{~nm}$ \\
\hline p-type layer & Amorphous Silicon & $20 \mathrm{~nm}$ \\
\hline Intrinsic layer & Amorphous Silicon & $200 \mathrm{~nm}$ \\
\hline n-type layer & Amorphous Silicon & $50 \mathrm{~nm}$ \\
\hline Back TCO & $\mathrm{ZnO}: \mathrm{Al}$ & $100 \mathrm{~nm}$ \\
\hline Back reflector & $\mathrm{Ag}$ & $200 \mathrm{~nm}$ \\
\hline
\end{tabular}




\section{ANALYSis of Simulated Results}

It is required to discuss the simulated results of the amorphous silicon solar cell without sidewall passivation, before discussing the simulated results of the modified design of amorphous silicon solar cell.

When sunrays enter the top glass layer, it generates electric field in that layer and photons are absorbed by the front TCO. Then the energy is passed downward through p-type layer. In amorphous silicon based p-i-n solar cell the surface charge density is greater in n-type layer. As the majority carriers of n-type layer are electrons and the majority carriers of p-type layer are holes.

Solar cell generates electric potential. So generated electric potential is high in n-type. Figure 2 shows the electric potential generated in the solar cell when there was no passivation and also for the modified design with sidewall passivation. The sidewall passivation prevented the leakage in the solar cell. Due to the sidewall passivation electric potential has increased in the modified design. The modified design of the amorphous silicon based solar cell generates more electric potential.

Figure 3 shows the graph of electric potential generated in the solar cell before adding any sidewall passivation. From the graph electric potential is high in n-type layer. The highest electric potential generated in n-type layer is $4.55 \mathrm{~V}$.

Figure 4 shows the graph of electric potential generated in a-Si solar cell, when the design is modified with sidewall passivation. The highest electric potential generated in n-type layer is $4.68 \mathrm{~V}$.

Solar cell generates electricity by converting the photon energy. Electrons flow from n-type layer toward the ptype layer and current flows in the opposite direction. Electric current flowing through per unit cross-sectional area of a solar cell is known as current density. As current flows from p-type layer, so current density is higher in ntype layer.

To calculate the efficiency of solar cell, short circuit current density, open circuit voltage and fill factor is necessary. From current density versus voltage graph short circuit current $\left(\mathrm{J}_{\mathrm{sc}}\right)$ and open circuit voltage $\left(\mathrm{V}_{\mathrm{oc}}\right)$ can be calculated. tion:

Fill factor of the solar calculated from the below equa-

$$
\mathrm{FF}=\frac{\mathrm{Voc}-\ln (\mathrm{Voc}+0.72)}{\mathrm{Voc}+1}
$$

Efficiency is the most important factor for the performance analysis of the solar cell. It is the ratio between the input power and output power. Efficiency of the solar cell can be calculated from the below equation.

$$
\text { Efficiency, } \eta=\frac{\text { Voc.Jsc.FF }}{P_{\text {in }}}
$$

Figure 5 shows current density versus voltage graph before adding sidewall passivation in the designed a-Si solar cell. According to the graph short circuit current $\left(\mathrm{J}_{\mathrm{sc}}\right)$ is $14.7 \mathrm{~mA} / \mathrm{cm}^{2}$ and open circuit voltage $\left(\mathrm{V}_{\mathrm{oc}}\right)$ is $0.87 \mathrm{~V}$.

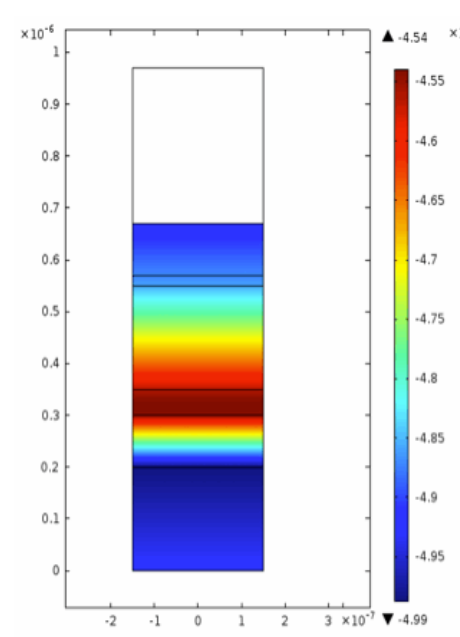

(a)

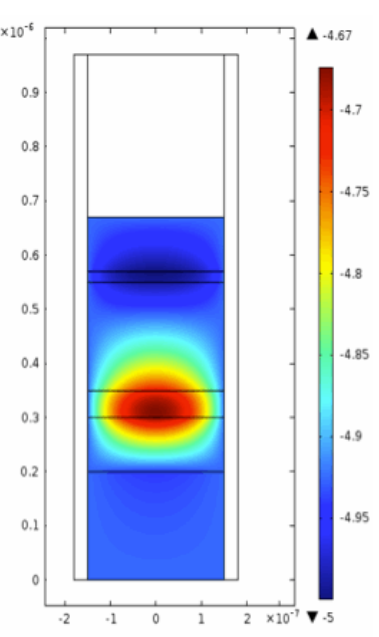

(b)
Figure 2. Electric potential generated in a-Si solar cell without passivation (a) \& electric potential generated in a-Si solar cell with sidewall passivation (b).

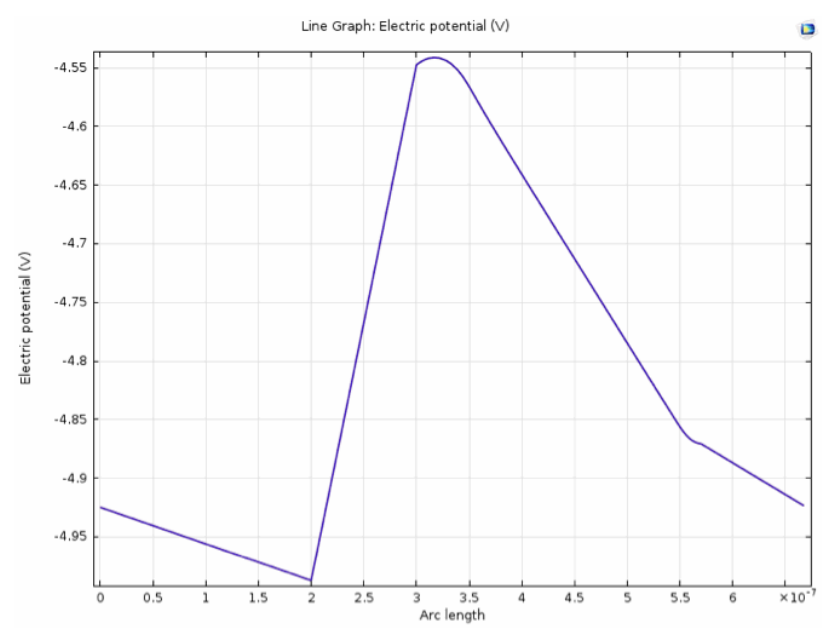

Figure 3. Electric potential generated in a-Si solar cell before adding passivation.

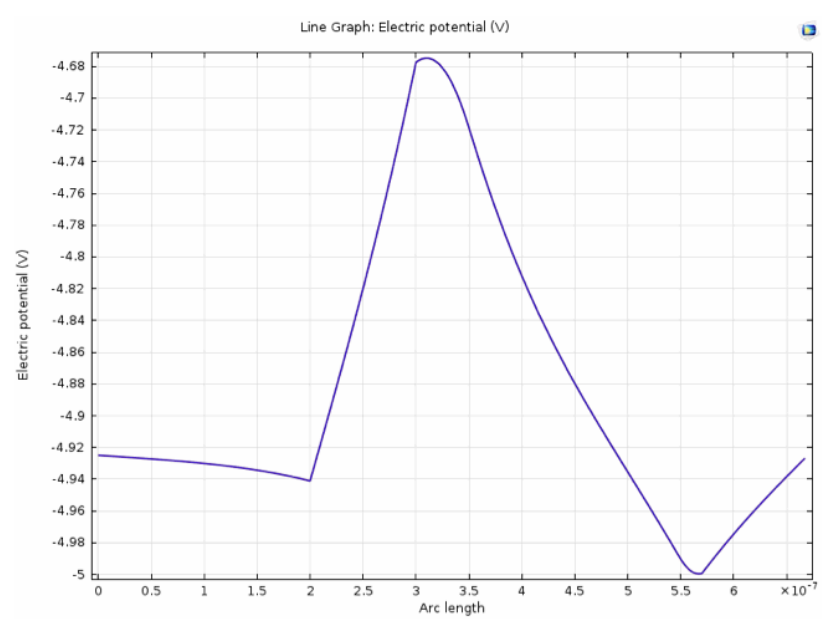

Figure 4. Electric potential generated in a-Si solar cell after adding sidewall passivation. 


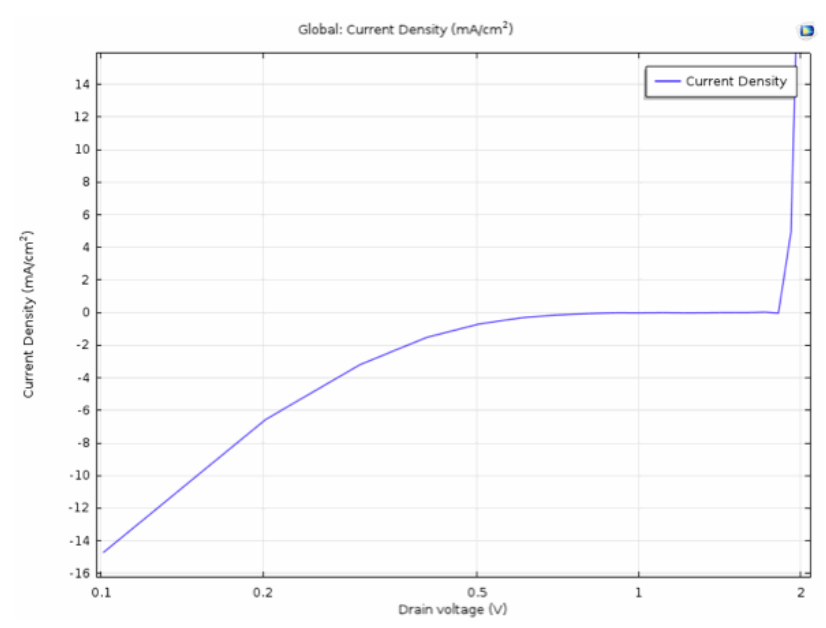

Figure 5. Current density versus voltage characteristics of a-Si solar cell before adding sidewall passivation.

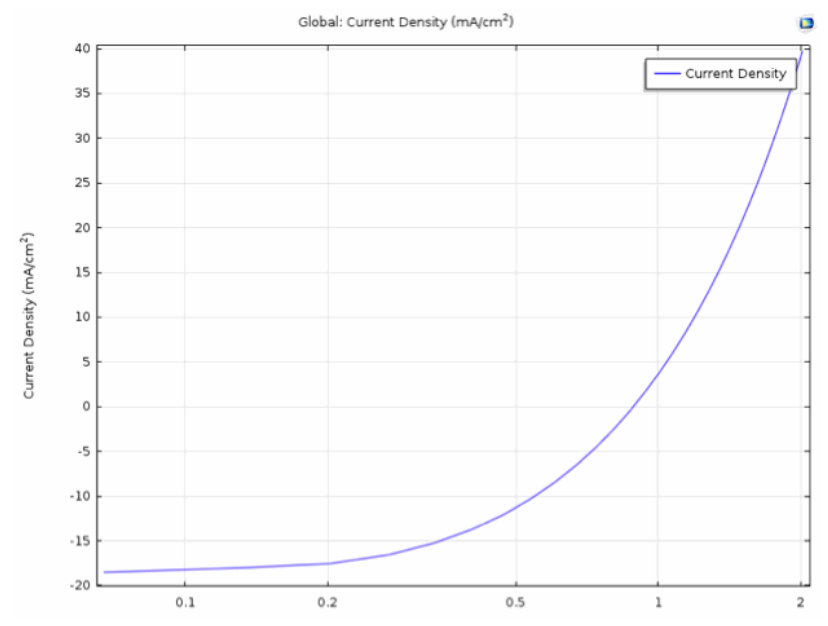

Figure 6. Current density versus voltage characteristics of a-Si solar cell after adding sidewall passivation.

TABLE II.

PHOTOVOLTAIC CHARACTERISTIC OF THE AMORPHOUS SILICON SOLAR CELL BEFORE AND AFTER SIDEWALL PASSIVATION

\begin{tabular}{|l|c|c|}
\hline \multicolumn{1}{|c|}{ Passivation status } & Before & After \\
\hline $\mathrm{J}_{\mathrm{sc}}\left(\mathrm{mA} / \mathrm{cm}^{2}\right)$ & 14.7 & 18.5 \\
\hline $\mathrm{V}_{\mathrm{oc}}(\mathrm{V})$ & 0.87 & 0.89 \\
\hline Fill Factor $(\%)$ & 86.9 & 87.12 \\
\hline Efficiency $(\%)$ & 11.11 & 14.34 \\
\hline
\end{tabular}

To increase the operational efficiency of optoelectronic devices passivation are used. Passivation reduces any leakage current inside the device. After adding passivation of $60 \mathrm{~nm}$ thick in a-Si solar cell, it reduces the leakage current in the solar cell. So the current density increased in the solar cell. Figure 6 shows current density versus voltage graph after adding sidewall passivation of $\mathrm{Al}_{2} \mathrm{O}_{3}$ in the designed a-Si solar cell. According to the graph short circuit current $\left(\mathrm{J}_{\mathrm{sc}}\right)$ is $18.5 \mathrm{~mA} / \mathrm{cm}^{2}$ and open circuit voltage $\left(\mathrm{V}_{\mathrm{oc}}\right)$ is $0.89 \mathrm{~V}$.

Passivation may be useful for optoelectronic devices to achieve highly efficient operation [8]. From table II it can be seen that before adding sidewall passivation in the designed solar cell, conversion efficiency is $11.11 \%$. After adding sidewall passivation, it prevents leakage current. So it increases current density of amorphous silicon solar cell. Thus efficiency increases after adding sidewall passivation. Conversion efficiency is $14.34 \%$. Conversion efficiency of designed a-Si solar cell has been increased by $29.07 \%$ after adding sidewall passivation of $\mathrm{Al}_{2} \mathrm{O}_{3}$.

\section{CONCLUSION}

According to the increasing demand of electric energy, the production of electric power is not increasing. Most of the electricity productive industries use natural resources to produce electricity. But the natural resources are limited. As a result, the natural resources are decreasing day by day to produce electricity. That's why an alternative resource should be used to produce electricity. And for this reason, renewable energies like solar energy can be a better option for producing electric energy. Applications of amorphous silicon based solar cell will increase if the conversion efficiency is increased significantly. After adding sidewall passivation, it was noted that the response of the device was enhanced. The most important factor to analyze the performance of the solar cell is fill factor and conversion efficiency. Passivation effectively suppresses the leakage in the solar cell. The short circuit current density $\left(\mathrm{J}_{\mathrm{sc}}\right)$ increased to $18.5 \mathrm{~mA} / \mathrm{cm}^{2}$, open circuit voltage $\left(\mathrm{V}_{\mathrm{oc}}\right)$ improved to $0.89 \mathrm{~V}$, and the fill factor increased from $86.9 \%$ to $87.12 \%$. Before adding sidewall passivation in a-Si solar cell, the conversion efficiency was $11.11 \%$ and after adding passivation was increased to $14.34 \%$. Conversion efficiency of amorphous silicon solar cell increased to $29.07 \%$ because of adding sidewall passivation of $\mathrm{Al}_{2} \mathrm{O}_{3}$. So it can be seen that after adding sidewall passivation of $60 \mathrm{~nm}$ thick in a-Si solar cell, the performance of the solar cell was improved.

\section{REFERENCES}

[1] "Why Solar Energy?" [Online]. Available: http://www.engineering.com/SustainableEngineering/RenewableE nergyEngineer-

ing/SolarEnergyEngineering/WhySolarEnergy/tabid/3893/Default. aspx. [Accessed: 08-Feb-2016].

[2] R. A Street "early research" in Hydrogen amorphous silicon, Cambridge University press, Cambridge, New York.

[3] Ruy S Bonilla (2013, july 10) electric field effect surface passivation for silicon solar cells [online]. Available: http://www.scientific.net/SSP.205-206.346

[4] “Amorphous silicon based solar cell." [Online]. Available: http://www.rci.rutgers.edu/ d dbirnie/solarclass/amorphousSi.pdf. [Accessed: 20-Jan-2016].

[5] J. M. Pearce, N. Podraza, R. W. Collins, M. M. Al-Jassim, K. M. Jones, J. Deng, and C. R. Wronski, "Optimization of open circuit voltage in amorphous silicon solar cells with mixed-phase (amorphous+nanocrystalline) p-type contacts of low nanocrystalline content," J. Appl. Phys., vol. 101, no. 11, p. 114301, 2007.

[6] Baruch, P., De Vos, A., Landsberg, P. T., \& Parrott, J. E. (1995). On some thermodynamic aspects of photovoltaic solar energy conversion. Solar Energy Materials and Solar Cells. http://dx.doi.org/10.1016/0927-0248(95)80004-2

[7] "Amorphous silicon solar cells: Solar Facts and Advice." [Online]. Available:http://www.solar-facts-and-advice.com/amorphoussilicon.html. [Accessed: 08-Feb-2016].

[8] J.Schmidt, AMerkle, R Brendle, B. Hoex m. C. M. Vande Sanden and W. M. M. Kessels, "surface Passivation of deposited A12O3," Progress in Photovoltaics: Research and Applications, vol. 6, PP 461-466, 2008.

[9] H. Kim, J Cho, Y. Park, and T. - Y. Seong, "Leakage Current Origins and passivation affect of GaN-based light emitting diodes favricated with Ag P-Contacts," Applied Physics Letters, vol. 92, no. 9 , p. $092115,2008$.

[10] Towards very low-cost mass production of thin-film silicon photovoltaic (PV) solar modules on glass. Elsevier B.V., 2005. 
[11] "Life Cycle Analysis of Silane Recycling in Amorphous SiliconBased Solar Photovoltaic Manufacturing | Joshua Pearce - Academia.edu." [Online]. Available: http://www.academia.edu/2310926/Life_Cycle_Analysis_of_Silan e_Recycling_in_Amorphous_Silicon-

Based_Solar_Photovoltaic_Manufacturing. [Accessed: 08-Feb2016].

[12] R. Crandall and W. Luft, "The Future of Amorphous Silicon Photovoltaic Technology",Prog. Photovolt: Res. Appl., vol. 3, no. 5, pp. 315-332, 1995.

[13] T. Söderström, F.-J. Haug, V. Terrazzoni-Daudrix, and C. Ballif, "Optimization of amorphous silicon thin film solar cells for flexible photovoltaics," J. Appl. Phys., vol. 103, no. 11, p. 114509, 2008 .

[14] "History of Solar Energy - Solar Energy.com." [Online]. Available: http://solarenergy.com/power-panels/history-solar-energy. [Accessed: 20-Jan-2016].

\section{AUTHORS}

Md. Mostafizur Rahman received the B.Sc. degree in electrical and electronic engineering from American International University-Bangladesh, Bangladesh in 2014. His fields of interest are renewable energy, antenna designing, wireless communications \& nanoelectronics.

Md. Moidul Islam received the B.Sc. degree in electrical and electronic engineering from American International University-Bangladesh, Bangladesh in 2014 with an excellent academic background. His fields of interest are solar cell designing, antenna designing, materials science, photonics \& nanoelectronics.

Mission Kumar Debnath received the B.Sc. degree in electrical and electronic engineering from American International University-Bangladesh, Bangladesh in 2015. His fields of interest are solar cell designing, electromagnetic waves \& nanoelectronics.

S. M. Saifullah received the B.Sc. degree in electrical and electronic engineering from American International University-Bangladesh, Bangladesh in 2015. His fields of interest are solar cell designing, image processing technology.

Samera Hossain received the B.Sc. degree in electrical and electronic engineering from American International University-Bangladesh, Bangladesh in 2014. Her fields of interest are solar cell designing \& nanoelectronics.

Nusrat Jahan Bristy received the B.Sc. degree in electrical and electronic engineering from American International University-Bangladesh, Bangladesh in 2014. Her fields of interest are solar cell designing, photonics \& nanoelectronics.

Submitted 13 May 2016. Published as resubmitted by the authors 10 June 2016. 